\title{
Tracking the decline of the world's largest seabream against policy adjustments
}

\author{
Sven E. Kerwath ${ }^{1,2, *}$, Denham Parker ${ }^{1}$, Henning Winker ${ }^{1,3}$, Warren Potts ${ }^{4}$, \\ Bruce Mann $^{5}$, Christopher Wilke ${ }^{1}$, Colin Attwood ${ }^{2}$ \\ ${ }^{1}$ Department of Agriculture, Forestry and Fisheries, Vlaeberg 8018, Cape Town, South Africa \\ ${ }^{2}$ Biological Sciences, University of Cape Town, Rondebosch 7700, South Africa \\ ${ }^{3}$ Centre for Statistics in Ecology, Environment and Conservation, Department of Statistical Sciences, \\ University of Cape Town, Rondebosch 7700, South Africa \\ ${ }^{4}$ Department of Ichthyology and Fisheries Science, Rhodes University, Grahamstown 6140, South Africa \\ ${ }^{5}$ Oceanographic Research Institute, PO Box 10712, Marine Parade 4056, Durban, South Africa
}

\begin{abstract}
For most rare marine species, abundance trends are poorly estimated. This uncertainty often translates into disagreement on management regulations, impeding conservation efforts when they are most urgently required. The world's largest sea bream, the red steenbras Petrus rupestris, has undergone a substantial and widely acknowledged decline during the $20^{\text {th }}$ century. Standardised probability of encounter over the last 3 decades was used to track red steenbras abundance trajectories in 2 regions, which together represent the species' distribution. The results predicted a reduction in abundance of $44 \%$ in the East region and $96 \%$ in the South-West region, from what was already considered to be a collapsed population at the start of the time series. The species is now largely confined to areas in the centre of its historical abundance. Content analysis of a recreational angling magazine revealed a concurrent $50 \%$ decrease in reported size between 1984 and 2012. Shore-based observer data (2009-2010) indicate that the impact of recreational fishers on this species far exceeded that of commercial fishers at the time. Regulations in the form of progressively more stringent catch and effort restrictions appear to have been largely ineffective, too lenient, implemented too late or were unsuitable to control fishing mortality for this species. This study highlights 2 fundamental challenges in management of rare marine fish species: (1) providing decision makers with a credible measure of abundance for species whose rarity limits data availability and (2) implementing effective policy changes before the specific measures become ineffective and obsolete.
\end{abstract}

KEY WORDS: Rare fishes - Content analysis · Probability of encounter - Fisheries regulations · Recreational fishing impact $\cdot$ Management failure $\cdot$ Red steenbras $\cdot$ Petrus rupestris

\section{INTRODUCTION}

Finding appropriate policy interventions to effectively conserve rare or severely overexploited marine species remains a challenge. The reason for this is threefold: (1) traditional fisheries reference points cannot be determined with certainty due to a lack of

\footnotetext{
${ }^{*}$ Corresponding author: svenk@daff.gov.za
}

catch and abundance information; (2) alternative approaches such as those used in the IUCN Red List, originally developed for terrestrial species, seldom find acceptance among the fishery management community (Musick et al. 2000, d'Eon-Eggertson et al. 2015, Collen et al. 2016); and (3) the effectiveness of management interventions cannot be easily evalu-

() The authors 2019. Open Access under Creative Commons by Attribution Licence. Use, distribution and reproduction are unrestricted. Authors and original publication must be credited. 
ated. The further a species has declined, the more severe these challenges become. Management decisions become increasingly subjective in the absence of reliable and current information - often to the detriment of conservation objectives - as the socioeconomic consequences of a 'false alarm' can be severe (Dulvy et al. 2004). This is particularly true for multi-user fisheries, as the desire to continue the exploitation and provide sector-specific concessions can result in strong political lobbying against mounting scientific evidence.

In this contribution, we developed 2 complimentary indices to track the abundance of rare, exploited species. The first index uses a standardised probability of encounter (SPE) based on commercial boat landings (Parker et al. 2016). This index of relative abundance is applicable when a species is rare or has declined to levels where it features only in a small proportion of landings, even when targeted. SPE, based on capture or landing data, is particularly suitable in instances where catch restrictions such as bag limits and changes thereof during the data series question the validity of catch per unit effort (CPUE)based indices. We used a simple simulation experiment to demonstrate that this index is able to accurately track abundance for rare species over a wide range of scenarios (see the Appendix). The second index is based on content analysis (CA) of a recreational angling magazine and examines the trends in the size of trophy fish reported, which would correlate positively with stock status (Richardson et al. 2006). We applied these indices to track the population trajectory of the red steenbras Petrus rupestris, Sparidae (Valenciennes, 1830).

The red steenbras is the largest species in the family Sparidae, reaching a maximum of $200 \mathrm{~cm}$ total length, a weight of up to $70 \mathrm{~kg}$ and an age of over $33 \mathrm{yr}$ (Smale 1988). It is endemic to the South African coast and is found between False Bay and St Lucia. Juvenile fish are highly resident on inshore reefs (10-50 m depth) in the Eastern and Western Cape Province (Kei Mouth to Cape Point). Adults are found on deeper offshore reefs (50-160 m) and undertake a north-easterly migration to the northern parts of the coast along the Eastern Cape and southern KwaZuluNatal Province (Smale 1988, Penney \& Wilke 1992). Adult red steenbras are apex predators on deep reefs, feeding mainly on reef fish such as cheilodactylids, clinids and small sparids. They also feed on squid, octopus and crustaceans. They are rudimentary hermaphrodites (functional gonochorists), with peak spawning occurring between August and October (Smale 1988). Most spawning takes place to the north of East London and on the offshore Agulhas Banks, and there is some indication of the formation of spawning aggregations. Maturity is reached at a length of $575 \mathrm{~mm}$ fork length and an age of $7 \mathrm{yr}$ (Smale 1988). Like many large, predatory, reef-associated fish species globally, the red steenbras has been in decline since the early $20^{\text {th }}$ century (Griffiths 2000). The decline is well-documented in scientific and popular literature (Tables S1-S3 in the Supplement at www.int-res.com/articles/suppl/m610p163_ supp.pdf) and led to the species being listed as Endangered on the IUCN Red List in 2014 (Mann et. al. 2014). Historically, red steenbras was an important component of both recreational and commercial boat-based hook-and-line fisheries throughout its distribution and was even caught by shore anglers. More recently, catches have diminished in most areas except in the historical centers of its distribution, where it is still caught in reasonable numbers (Mann \& Kerwath 2013).

Although there has been widespread consensus throughout the years that fisheries management interventions are urgently required (Penney \& Wilke 1992), the extent of sector-specific impacts remained in dispute (Griffiths \& Wilke 2002, Fennessy et al. 2003) as detailed sector-specific catch data were not available or had not been analysed. Consequently, perceptions of the magnitude of the decline and appropriate management regulations differed among stakeholders and regions, in particular when catches in some areas remained hyperstable. Despite ongoing disconsent, historical attempts to manage red steenbras have been extensive. Species- and fisheryspecific regulations, including commercial effort reduction, daily bag limits, minimum size limits, a closed season and several closed areas have been implemented since the onset of fishery management interventions in 1984 (Table 1). The most stringent intervention in the form of a complete moratorium on catches of red steenbras by all fishing sectors in 2012 was set aside for the recreational sector after a court challenge by sports anglers succeeded largely on procedural grounds (High Court of South Africa, Case No. 31629/13); the species can still be retained by recreational anglers under strict bag and size limits, but no sale is permitted.

Our study evaluated the effectiveness of consecutively stricter fishery management interventions in relation to biological traits, fishing behaviour and observed trends. To gain an understanding of the relative impact of the recreational and commercial sectors on red steenbras stock, we analysed land-based fishery observer data (2009-2010) from access points 
in the centre area of its historical abundance. Illustrated for a single, iconic species, this work has application for fisheries where competing recreational and commercial fishing sectors negatively impact the conservation of rare or already depleted fishes.

\section{MATERIALS AND METHODS}

\subsection{Commercial catch and effort data}

Commercial catch and effort data from 1985 to 2011, the period from the start of the mandatory reporting of commercial catch returns to the implementation of a moratorium on commercial capture of red steenbras, were extracted from the National Marine Linefish System (NMLS), a database that houses mandatory commercial and voluntary recreational fishery-observer and fishery-independent catch data. The raw data are comprised of daily commercial catch (kg) per species per boat per day as reported by the skipper, as well as vessel registration number, crew number, hours at sea, date and catch location. We referenced the reported catch location to the midpoints of $5 \times 5$ min latitude and longitude grid cells (Winker et al. 2013). For the analyses, the data set was divided into 2 regions along the coast of South Africa: (1) South-West, from Cape Point to Tsitsikamma and (2) East, from Tsitsikamma to Durban. These 2 areas represent the primary fishing grounds for red steenbras and reflect the geographical division of the fishery based on species composition (Winker et al. 2013, Blamey et al. 2015). A total of 612209 (South-West) and 614242 (East) mandatory daily commercial catch return records were available. Data were eliminated from the analyses for several reasons (c.f. Winker et al. 2013). Analyses were restricted to catch locations at which a minimum of 10 positive catch records of red steenbras were reported. Catch records with improper classification of species were removed, including records that referred to higher-order taxonomic groups (e.g. Sparidae) or polyphyletic artificial groups (e.g. redfish). Additionally, records with large catches (>5 kg) of squid Loligo vulgaris were omitted, because fishers usually target these species separately with little or no bycatch. Records were rejected if information about crew size and hours at sea was missing. Time at sea and crew size were restricted to a maximum of $12 \mathrm{~h}$ and 12 fishers, respectively, to remove the impact of the few large vessels that inconsistently reported catches after spending several consecutive days at sea. Crew number was omitted as a potential
Table 1. Details of changes in fisheries regulations for red steenbras Petrus rupestris during the time period analysed in this study (years are labelled a-j for ease of reference in Figs. 2 \& 4). References to the government gazettes are included in Table S4

Year Detail of regulations

(a) 1984 Establishment of 2 categories of commercial activity; namely, full commercial linefishers designated category ' $\mathrm{A}$ ' and semi-commercial linefishers designated category ' $\mathrm{B}$ '. Introduction of a minimum size limit (MSL) of $250 \mathrm{~mm}$ total length (TL) for all, no daily bag limit (DBL) for category 'A' commercial but a DBL of 5 fish person ${ }^{-1} \mathrm{~d}^{-1}$ (pppd) for category 'B' commercial and recreational fishers

(b) 1990 Introduction of a 3 mo closed season (1 Sep-30 Nov) for all sectors

(c) 1991 Increase of the MSL to $400 \mathrm{~mm}$ for all

(d) 1992 Introduction of a DBL of 10 fish pppd for category ' $A$ ' commercials with the retention of a DBL of 5 fish pppd for category 'B' commercial and recreational fishers

(e) 1994 Decrease of DBL to 5 fish pppd for category 'A' commercials and a reduction of the DBL to 2 fish pppd for category 'B' commercials and recreational fishers

(f) 1997 Decrease of the DBL to 2 fish pppd for category 'A' commercials, thus making for a universal DBL of 2 fish pppd for all sectors

(g) 1998 Dropping of the closed season for all sectors

(h) 2000 Declaration of emergency in the linefishery, which resulted in a reorganisation of the commercial sector under one general category of commercial and a reduction of commercial fishing effort of $70 \%$, phased in gradually until the conclusion of the long term fishing rights allocation in 2007

(i) 2005 Increase of MSL to $600 \mathrm{~mm} \mathrm{TL}$, decrease of DBL to 1 fish pppd (for all sectors), reintroduction of 3 mo closed season (1 Sep-30 Nov for commercials and 2 mo 1 Oct-30 Nov for recreational fishers)

(j) 2012 Full moratorium on capture of red steenbras for all target fisheries. The moratorium was set aside for the recreational sector following a court challenge by sports anglers in 2013

predictor variable as records were found to be incomplete and in some instances unrealistic. While crew size has been found to be an important variable for predicting positive catch rates (Winker et al. 2013), an analysis on a subset of data with complete records indicated that it explained minimal variation in the probability of encounter. The final data set comprised 494533 (South-West) and 349656 (East) catch return records. 


\subsection{Clustering of catch data to identify fishing strategies}

We clustered catch data based on species composition to objectively identify and select fishing strategies that targeted red steenbras (Jiménez et al. 2004, Stephens \& MacCall 2004) and to remove variation in the data caused by non-targeted effort (Winker et al. 2013). The non-hierarchical clustering method, 'Clustering Large Application' (CLARA) (Kaufman \& Rousseeuw 1990, Struyf et al. 1996), an extension of the 'Partitioning Around Medoids' (PAM) method suitable for large data sets (Kaufman \& Rousseeuw 1990), was used. Data were first prepared by constructing matrices comprising daily CPUE records by species for each region. We then standardised CPUE into relative proportions by weight to eliminate the influence of catch volume and then fourth-root transformed CPUE to allow less dominant target species to contribute to the similarity among catch compositions (Clarke \& Warwick 2001). The matrices were further restricted to species or species groups that contributed at least $0.1 \%$ to the total landings per region, notwithstanding the species under assessment. The resultant data comprised 33 and 25 species for the South-West and East coast regions, respectively.

We applied a principal component analysis (PCA) to reduce the dimensions of the catch composition matrix to principal components (PCs) (Pelletier \& Ferraris 2000, Deporte et al. 2012). The number of nontrivial PCs was determined based on non-graphical solutions for Catell's Scree test in association with the Kaiser-Guttman rule (eigenvalue $>1$ ). The optimal number of clusters was then taken as the number of retained PCs +1 (Winker et al. 2014). Finally, the identified clusters were coded and each record was assigned a fishing strategy as a categorical variable (Winker et al. 2013, Mann et al. 2016).

\subsection{Standardisation of the probability of encounter}

Generalized additive models (GAMs) were used to examine the relationships between the probability of encounter ( 0 : absent; 1 : present) and selected predictor variables, assuming a binomial error model. Catch data from each region were analysed separately, and the full GAMs included the smoothing functions for the variables 'year', 'month', 'hours at sea', 'longitude' and 'latitude' as follows:

$$
\begin{aligned}
\operatorname{logit}(p)=\alpha+f_{1}(\text { year })+f_{2}(\text { month }) & \\
& +f_{3}(\text { lat }, \text { long })+f_{4}(\text { hours })+\text { FS }
\end{aligned}
$$

where logit denotes the binomial link function, $p$ is the probability of landing at least one individual under assessment per boat trip, $\alpha$ is the intercept, $f_{1-4}$ denote thin plate regression spline smoothers (Wood 2006) and FS is the fishing strategy cluster that was treated as a categorical variable (Winker et al. 2013, Carvalho et al. 2014).

The annual probability of encounter was standardised by fixing all covariates other than year and grid cell (longitude/latitude) in the prediction data set. First, the expected probability of encounter $\hat{P}_{1, Y}$ for location $l$ in year $y$ was standardised to the month with highest mean number encounters and to the median hours at sea. The expected annual mean probability of encounter $\hat{P}_{y}$ was then calculated as an average across all grid cells:

$$
\hat{P}_{y}=\frac{1}{n_{l}} \sum_{l} \hat{P}_{l, Y}
$$

\subsection{Recreational catch records from a popular magazine publication}

Recreational fisheries data were obtained using a CA of Ski-boat Magazine. This magazine was established in 1985 and focuses on recreational fishing from vessels in offshore waters. The CA comprised a detailed examination of the editorial, featured articles, regular columns, letters from readers, and reader catch submissions of each bimonthly magazine edition between 1985 and 2012. When a photograph with a caption or written catch information for a red steenbras was identified, all available information such as year, month, species, size (length/weight) and location of the capture were recorded in a database. Length records were converted to weight (using the conversion equation in Smale 1988) where necessary and plotted per year as the mean weight and $95 \%$ confidence intervals.

\subsection{Effectiveness of management regulations}

To examine the population response to individual changes in management regulations, the implementation years were superimposed on the landings, encounter probability and CA time series.

\subsection{Recreational and commercial on-site observer data}

Catch and effort information derived from boat landing site inspections were sourced from the NMLS for the period 2009-2010. The landing site 
inspections were conducted randomly with regard to weekdays and weather conditions and covered 12 major commercial landing sites for the linefishery. Data from 3 access points in the centre of the remaining distribution of red steenbras, Port Elizabeth, Port Alfred and East London, were included in the analysis. The total number of on-site sampling events was 375 and 325 in 2009 and 2010, respectively. During each sampling event, the number of commercial and recreational boat outings was recorded, as well as catch data from a random subsample of boats. The sample sizes of individual boat catches were $n=530$ in 2009 and $n=270$ in 2010 for recreational sector and $n=478$ in 2009 and $n=430$ in 2010 for the commercial sector. Catch data were separated by species and CPUE was expressed as the daily catch in numbers of red steenbras per boat day (catch outing ${ }^{-1}$ ).

Because the total commercial boat effort (2400 and 2375 boat days in 2009 and 2010, respectively) was available from mandatory catch returns for the region, it was possible to upscale the observed recreational effort $\left(O E_{\mathrm{Rec}_{y}}\right)$ as the product of total commercial effort $\left(O E_{\operatorname{Rec}_{y}}\right)$ and the ratio of $O E_{\mathrm{Rec}_{y}}$ to observed commercial effort $\left(O E_{\mathrm{Com}_{y}}\right)$ to obtain an estimate of the total recreational effort $\left(E_{\operatorname{Rec}_{y}}\right)$, such that:

$$
E_{\operatorname{Rec}_{y}}=\frac{1}{n_{y}} \sum_{y} E_{\mathrm{Com}_{y}} \frac{O E_{\operatorname{Rec}_{y}}}{O E_{\mathrm{Com}_{y}}}
$$

where $n_{y}$ is the number of years. The total catch in number of fish per species per year per sector was then calculated as:

$$
\text { Catch }_{j}=\frac{1}{n_{y}} \sum_{y} \text { CPUE }_{j, Y} \text { Effort }_{j, y}
$$

where $\mathrm{Catch}_{j}$ is the average yearly catch by sector $j$ (commercial or recreational), $\mathrm{CPUE}_{j, y}$ is the mean CPUE for sector $j$ in year $y$, and Effort $_{j, y}$ is number of boat days by sector $j$ in year $y$.

To account for uncertainty, a non-parametric bootstrap procedure was conducted to obtain $95 \%$ confidence intervals for total CPUE, effort and catch estimates. For each of the 500 bootstrap simulations, new effort and CPUE data sets were generated by random drawing with replacement records from each of the original effort and CPUE data sets for each year $y$ and sector $j$. In this way, each bootstrap iteration produced a new set of random records of $\mathrm{CPUE}_{j, y}$ and Effort $_{j, y}$, which were stratified by sector and year and used to calculate new estimates of Catch $_{j}$ from Eqs. (3) \& (4). The percentile method (Buckland 1984) was used to estimate 95\% confidence intervals from the resulting bootstrap vectors, where the $2.5^{\text {th }}$ and $97.5^{\text {th }}$ percentiles were chosen to obtain the lower and upper $95 \%$ confidence intervals, respectively.

\section{RESULTS}

\subsection{Clustering of catch data to identify fishing strategies}

Commercial catch returns data indicated that red steenbras only contributed trivial proportions to the catch composition in any of the 6 identified 'fishing strategy' clusters for the South-West region (Fig. S1 \& Table S5 in the Supplement). According to the optimal 'fishing strategy' cluster identified, the probability of catching a red steenbras in an outing was only $3 \%$. The dominant species of encounter probability for this cluster were reef-associated sparids (Fig. S1), specifically hottentot Pachymetopon blochii (78\%) and roman Chrysoblephus laticeps (70\%), and also the other larger sparids, such as dageraad Chrysoblephus cristiceps and red stumpnose Chrysoblephus gibbiceps, were most frequently encountered in this cluster. In the East region, the optimal fishing strategy cluster for red steenbras had a $13 \%$ probability of catching this species. The most commonly encountered species in this cluster was carpenter Argyrozona argyrozona (92\%), followed by other reef-associated seabreams, again including dageraad, red stumpnose and roman (Fig. S2 in the Supplement). Red steenbras contributed considerably less to the catch composition of the other 4 clusters in the East region.

\subsection{Probability of occurrence distribution over time}

From 1985-1987, there was a relatively high probability of capturing red steenbras along most of the South and East Coast (Fig. 1A). However, the spatial extent of these 2 areas of high capture probability had decreased appreciably by 2011 (Fig. 1B). There was a marked contraction in the distribution range in these to 2 areas by the 2009-2011 period, with relatively high red steenbras capture probability only off Cape Agulhas and north-east of Algoa Bay. There was consistent distribution of recorded fishing effort over time (\% fishing trips per $20 \times 20 \mathrm{~km}$ grid per region) between these 2 periods of assessment.

\subsection{Temporal catch and encounter probability trends}

Over the time series from 1985 to 2011, annual commercial catches declined in the South-West from 12610 to $392 \mathrm{t}$ (a decline of $96.9 \%$ ) and from 27215 to 


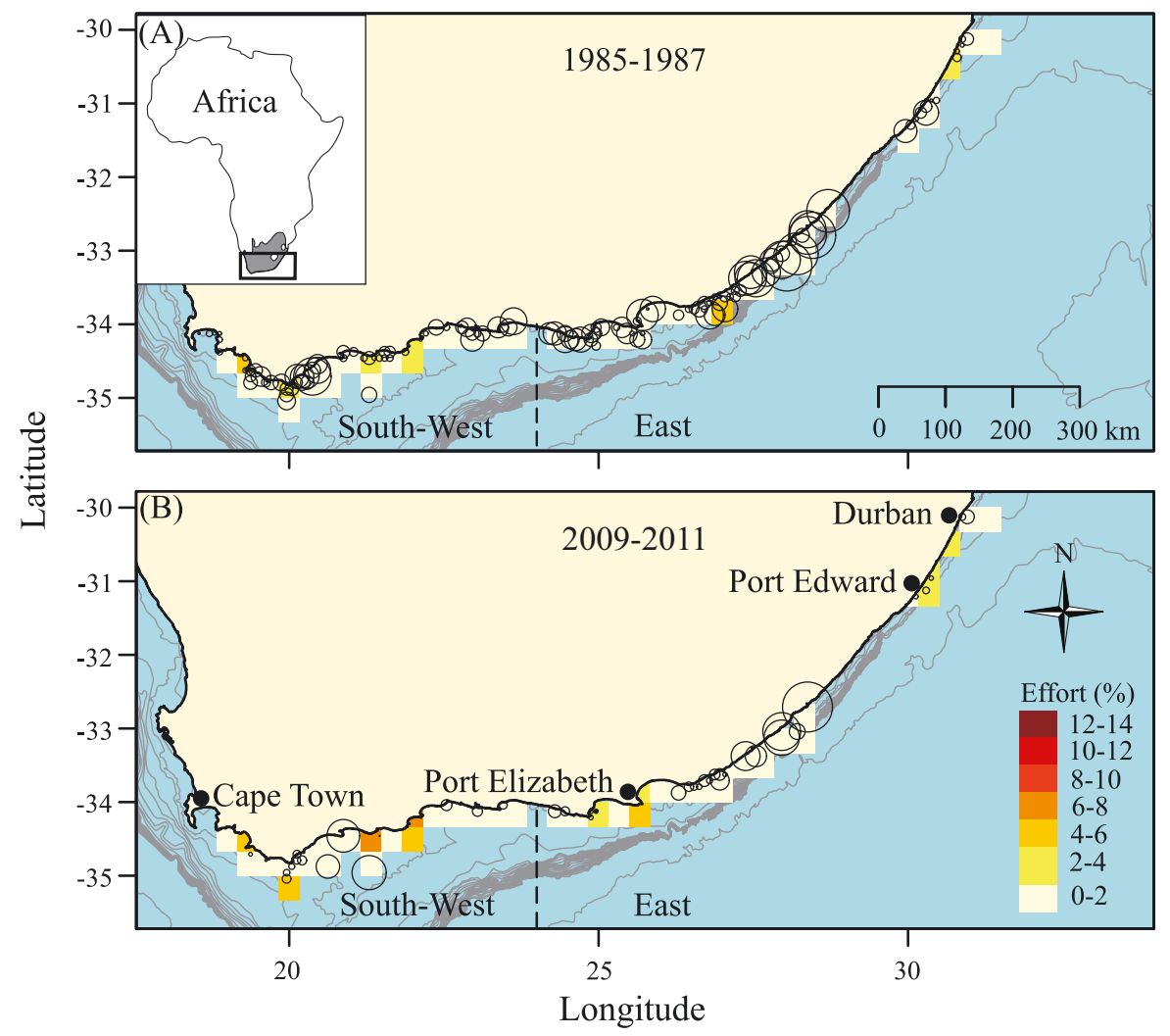

Fig. 1. Comparison of spatial distribution of normalized probability of encounter of red steenbras Petrus rupestris in commercial linefish catches along the South African coast between the periods (A) 19851987 and (B) 2009-2011. Dashed vertical line: boundary between the South-West and East region; grey circles: scaled to represent probability of encounter of a red steenbras; coloured boxes: relative distribution of fishing effort (percentage of fishing trips per $20 \times 20 \mathrm{~km}$ grid per region)
$977 \mathrm{t}(96.4 \%)$ in the East (Fig. 2). There was a $96 \%$ decrease in the SPE of a red steenbras in the SouthWest region between $1985(\mathrm{SPE}=16 \%)$ and 2011 $(\mathrm{SPE}=0.6 \%)$ (Fig. 3A). The trend was similar, but less severe, in the East region, where a $44 \%$ decline between $1985(\mathrm{SPE}=27 \%)$ and $2011(\mathrm{SPE}=15 \%)$ was estimated (Fig. 3B).

\subsection{Recreational CA}

The mean weight of red steenbras reported in recreational catches showed a peak of $42 \mathrm{~kg}$ at the beginning of the data series and was relatively stable until 2005 before rapidly declining thereafter to a low of $24 \mathrm{~kg}$ (Fig. 4).

\subsection{Effectiveness of management regulations}

Consecutive implementation of management interventions may have slowed the decline in the red steenbras population during the $1990 \mathrm{~s}$, but failed to arrest the stock collapse. Only the intervention in 2000 (a $70 \%$ reduction in commercial boats, phased in over a number of years) was followed by a clear positive average trend in encounter probability in the
East zone (Fig. 3A). However, this regulation was implemented gradually and only came to full effect in 2005, after which the trend reversed (Fig. 3A). The overall trend in capture probability declined in the South-West. However, there was a slight upward trend in capture probability in the South-West in the

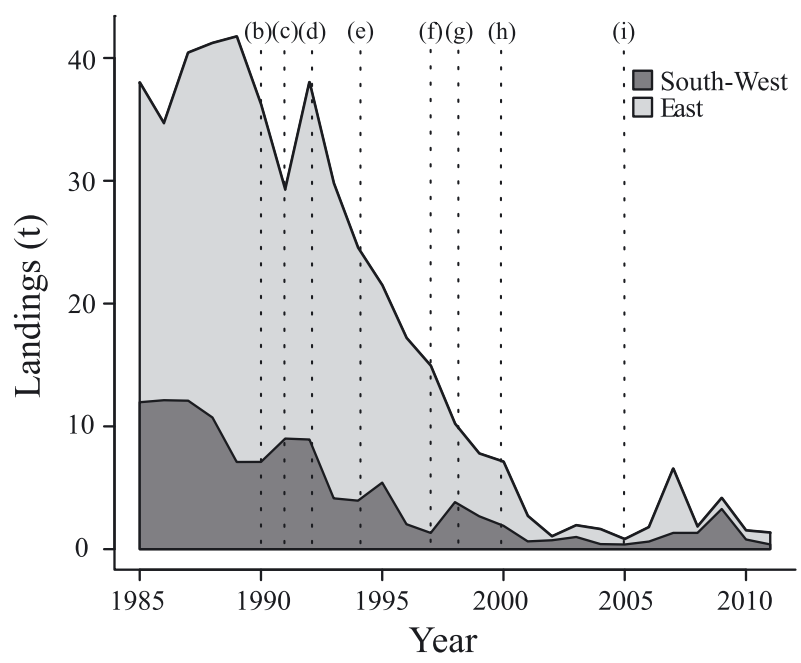

Fig. 2. Time series of reported landings (metric tonnes) of red steenbras in commercial linefish catches (1985-2011) for 2 regions along the South African coast prior to the moratorium on commercial catches in 2012. Dashed vertical lines: changes in management regulations outlined in Table 1 

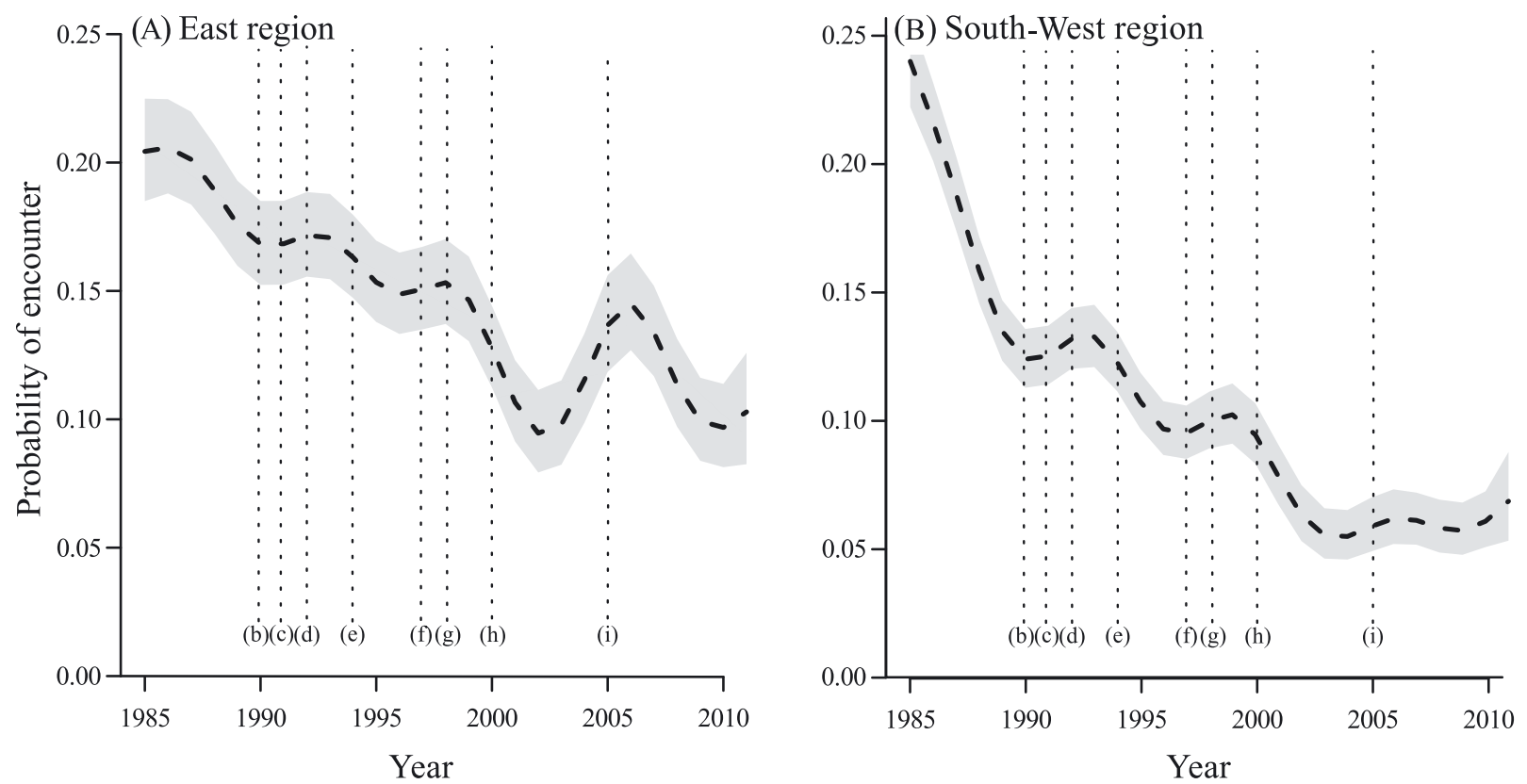

Fig. 3. Time series of standardized capture probabilities for red steenbras Petrus rupestris in commercial linefish catches (1985-2011) for the (A) East and (B) South-West regions along the South African coast. Grey shading represents 95\% confidence intervals. Dashed vertical lines: changes in management regulations outlined in Table 1

period after 2005, when more stringent size and bag limits were implemented (Fig. 3B). The mean weight of the reported recreational catch remained relatively stable until the last regulation change in 2005 but decreased rapidly thereafter (Fig. 4).

\subsection{Recreational and commercial effort and estimated relative impact}

Observers recorded a total of 2029 recreational and 1432 commercial linefish boat outings at launch sites in Port Elizabeth, Port Alfred and East London (East region) in the years 2009 and 2010, respectively. The total commercial effort, which was calculated from the mandatory catch return data, was 2242 and 2209 boat days in 2009 and 2010, respectively, corresponding to an observer coverage for the commercial linefishery of approximately $30 \%$. Assuming a similar observer coverage at these launch sites for the recreational sector, their effort measured as boat days per year was 1.41 (95\% CI: 1.23-1.63) times higher than the commercial effort.

Average CPUE estimates for red steenbras were calculated based on 980 commercial and 807 recreational catch inspections. Average recreational CPUE for red steenbras was 0.106 fish per boat day $(95 \%$ CI: 0.079-0.140), and was 4 times higher than the average commercial CPUE of 0.026 (95\% CI: 0.0140.0402). By upscaling according to sector-specific

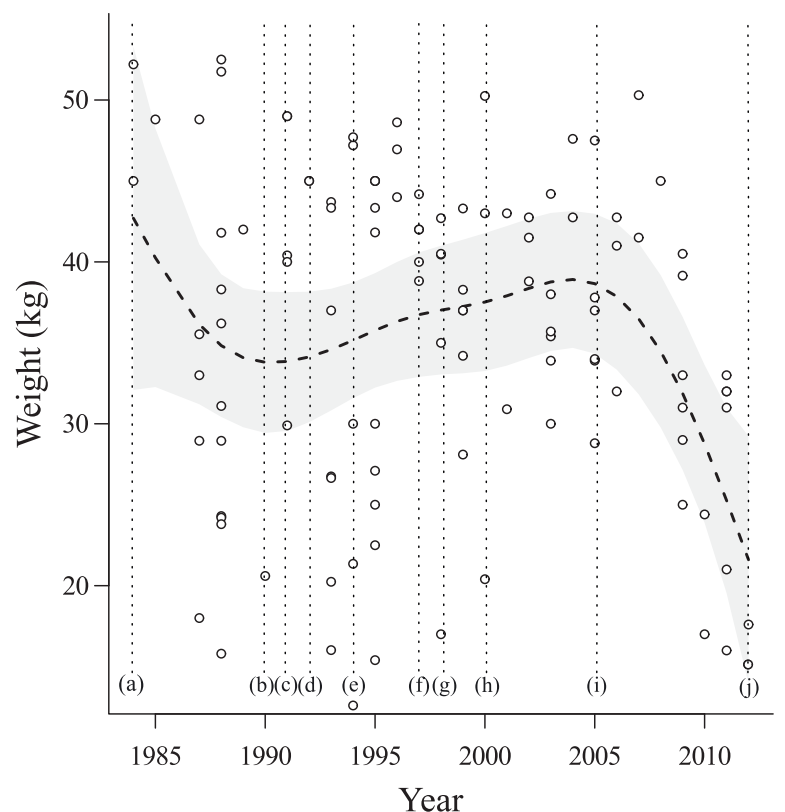

Fig. 4. Time series of reported weight (1985-2011) of recreationally caught red steenbras Petrus rupestris based on content analysis of Ski-boat Magazine along the entire South African coast. Grey shading repsents $95 \%$ confidence intervals. Dashed vertical lines: changes in management regulations outlined in Table 1

effort data, the total annual recreational catch for red steenbras was estimated to be 335.6 (95\% CI: 222.1449.13) individuals, compared to 58.8 (95\% CI: 31.9-89.5) for the commercial sector. 


\section{DISCUSSION}

Accurate fisheries assessment is dependent on reliable indices of fish abundance and estimates of the total catch. When assessing rare species, these indices may be associated with unacceptably high variability such that conventional methods can seldom be successfully applied. In addition, the implementation of management regulations such as bag limits effectively distort the relationship between CPUE and relative abundance, making this type of index unusable. To address this challenge for red steenbras, we instead inferred its status by considering 2 alternative indices: SPE and CA. These indices are contextualized with historical literature (Tables S1 \& S2 in the Supplement) and a timeline of sequential management interventions. SPE may reduce the variability of abundance indices for species that are so rare that they are encountered in a small proportion of the discrete effort records. Central to inferring trends in relative abundance from SPE for rare species is the assumption that if the SPE decreases below a certain threshold, the information content in the non-zero observations is minimal and the relationship between SPE and abundance becomes approximately linear close to its origin (see the Appendix). In the case of red steenbras, SPE was represented by daily boat landings. CA, on the other hand, is a lowcost method that has the potential to corroborate other methods in 'data poor' situations (e.g. Sadovy et al. 2003, Richardson et al. 2006, Fairclough et al. 2014).

The perpetual decline of the red steenbras since the early $20^{\text {th }}$ century is well documented (Mann \& Kerwath 2013, our Table S1 in the Supplement). At the beginning of the time series analysed in this study, the red steenbras population was already perceived to be under severe pressure (Penney \& Wilke 1992, Penney et al. 1999), and abundance was estimated to have declined by more than $90 \%$ compared to historical reference points (1931-1933) (Griffiths 2000, our Table S1). Range shrinkage was associated with the decline. Records of abundant red steenbras catches in the west, notably False Bay around 1900, and even Table Bay in the decades preceding that, attest to a collapse of greater proportion than can be estimated from modern catch records emanating predominantly in the central and eastern part of the historical range (Attwood 2015). Assuming a linear relationship between SPE and abundance and accepting the decline of red steenbras abundance estimated by Griffiths (2000), our study indicates that the red steenbras abundance has been reduced to less than
$5 \%$ of the pre-exploitation level and its range has further contracted.

The trends documented for red steenbras mimic the evolution of many fisheries around the world, beginning with an initial fishing-down phase by the commercial sector and progressive depletion along the fishes' range. As profitability of the fishery becomes marginal for commercial fishers, their focus may shift to other target species, but the subsidised effort of recreational fishers is not subject to the same dynamic. The relative impact of the recreational sector before the moratorium on commercial catches of red steenbras in 2012 was already 5 to 7 times higher than that of the commercial sector. However, this ratio is most likely conservative as observers did not record data at many of the recreational launch sites. Once recreational fisheries begin dominating the fishing effort, declines become increasingly difficult to detect. This is because there are few long-term monitoring programs of recreational fisheries around the world and the complex behaviour of recreational fisheries, which include rapid shifts in effort distribution (Post et al. 2002), efficiency (Griffiths et al. 2013) and the desire to target large trophy species (Shiffman et al. 2014). Nevertheless, the results of the CA in this study provided further evidence of a collapse.

Our results provide strong evidence for the continued decline of the red steenbras stock over the last $27 \mathrm{yr}$, since the formal recognition (i.e. regulation by permitting) of the linefishery in 1985 (Attwood et al. 2013) and little evidence for a lasting positive impact of the management measures. The drastic reduction of the commercial effort in 2000 (Table 1h), which was followed by a brief positive trend in SPE, was the only management intervention that appeared to have an effect in the East region.

Each of the commonly applied restrictions (bag, size, area and season limits) is typically only effective in particular circumstances. Enforcement of speciesspecific regulations in the South African boat-based linefishery has been challenging (Sauer et al. 1997), but reasonable enforcement structures exist in the form of shore patrols, patrol vessels, mandatory vessel monitoring systems and mandatory daily catch reporting by species and area for boat-based commercial fishing. Combinations of restrictions can be synergistic or antagonistic. Woodward \& Griffin (2003) argue that a combination of certain measures can increase the overall fishing mortality of the targeted species. Success of size limits and bag limits are dependent on the encounter rate of fishes of desirable size. In the case of red steenbras, the bag limits were seldom attained and size limits did not influ- 
ence fishing mortality (Smale 1988) due to the spatial disaggregation of small and large individuals. In areas where large fish aggregate, bag limits might have had the potential for success amongst commercial operators. However, when bag limits are used in combination with size limits, it may lead to an increase in the prevalence of discarding and highgrading. Large red steenbras are typically caught on deep $(70+\mathrm{m})$ reefs, making them susceptible to barotrauma (Kerwath et al. 2013b) and post-release mortality.

Seasonal limits are most effective for species if they coincide with life-history bottlenecks, i.e. spawning or feeding aggregations. In general, closed seasons are of limited effect for long-lived species, if they are equally susceptible in the open season. Red steenbras do aggregate, but the available evidence on the timing of these aggregations is vague and the species is consistently available at known aggregation sites outside the closed seasons (Fennessy et al. 2003, S. E. Kerwath unpubl. data). Catch rates from such higher density core areas can easily disguise a decline of species and result in overly optimistic perception of the stock status. Some of the most dramatic stock collapses globally can be ascribed to the misinterpretation of hyperstable catch data, when catch rates decline across the extended range, yet remain fairly stable within the centre of the distribution of the species (Hilborn \& Walters 1992, Rose \& Kulka 1999).

Marine Protected Areas (MPAs) are effective for some South African reef fishes (Buxton \& Smale 1989, Kerwath et al. 2013a). South Africa has created a series of MPAs along the range of the red steenbras, and most of them harbour the species in its juvenile phase (Solano-Fernandez et al. 2012). MPAs are likely to offer some measure of protection by ensuring that a proportion of juvenile fish escape capture and progress to adulthood in deeper water. Most known deep-reef aggregation sites of adult red steenbras fall outside current MPAs and only the establishment of a network of offshore MPAs in South Africa, a process that is currently in its public consultation phase, may also offer some protection for adults.

\section{CONCLUSIONS}

The portfolio of evidence from historical information and a combination of 2 independent abundance indices suggests a long-term decline of red steenbras abundance over the last $150 \mathrm{yr}$. Regulations were introduced only in the last quarter of this period, but these have not produced any lasting recovery of the species. A combination of factors has contributed to the failure of management interventions, but we now believe that (1) the effect of the regulations was not adequately considered and (2) regulations were simply implemented too late. The fate of the red steenbras mirrors that of many other marine species that become rare and where there is large uncertainty around their abundance. The complete cessation of fishing on this species, as has been successfully implemented on species such as the goliath grouper in Florida (McClenachan 2009), in combination with the implementation of the proposed offshore MPAs where no fishing is allowed, is likely the only means to assure a recovery.

Acknowledgements. We thank the Linefish Scientific Working Group and the Linefish Section of the Fisheries Management Branch of the Department of Agriculture, Forestry and Fisheries, South Africa. This work was partially funded through the National Research Foundation South Africa, Grant 97969.

\section{LITERATURE CITED}

Attwood CG (2015) More red steenbras big picture. Ski-Boat Magazine May/June 2015:13-14

Attwood CG, Booth AJ, Kerwath SE, Mann BQ and others (eds) (2013) A decade after the emergency: the proceedings of the $4^{\text {th }}$ linefish symposium. South Africa Report Series 2013/Marine/001. World Wildlife Fund (WWF) for Nature, Cape Town

Blamey LK, Shannon LJ, Bolton JJ, Crawford RJ and others (2015) Ecosystem change in the southern Benguela and the underlying processes. J Mar Syst 144:9-29

*Buckland ST (1984) Monte-Carlo confidence intervals. Biometrics 40:811-817

* Buxton CD, Smale MJ (1989) Abundance and distribution patterns of three temperate marine reef fish (Teleostei: Sparidae) in exploited and unexploited areas off the southern Cape coast. J Appl Ecol 26:441-451

Carvalho F, Ahrens R, Murie D, Ponciano JM, Aires-da-Silva A, Maunder MN, Hazin F (2014) Incorporating specific change points in catchability in fisheries stock assessment models: an alternative approach applied to the blue shark (Prionace glauca) stock in the south Atlantic Ocean. Fish Res 154:135-146

Clarke KR, Warwick RM (2001) Changes in marine communities: an approach to statistical analysis and interpretation. Primer-E, Plymouth Marine Laboratory, Plymouth

Collen B, Dulvy K, Gaston KJ, Ga U and others (2016) Clarifying misconceptions of extinction risk assessment with the IUCN Red List. Biol Lett 12:20150843

Deporte N, Ulrich C, Mahévas S, Demanèche S, Bastardie F (2012) Regional métiers definition: a comparative investigation of statistical methods using a workflow applied to international otter trawl fisheries in the North Sea. ICES J Mar Sci 69:331-342

* d'Eon Eggertson F, Dulvy NK, Peterman RM (2015) Reliable identification of declining populations in an uncertain world. Conserv Lett 8:86-96 
Dulvy NK, Ellis JR, Goodwin NB, Grant A, Reynolds JD, Jennings $S$ (2004) Methods of assessing extinction risk in marine fishes. Fish Fish 5:255-276

Fairclough DV, Brown JI, Carlish BJ, Crisafulli BM, Keay IS (2014) Breathing life into fisheries stock assessments with citizen science. Sci Rep 4:7249

Fennessy ST, McDonald AM, Mann BQ, Everett BI (2003) An assessment of the recreational and commercial skiboat fishery in the Transkei. Afr J Mar Sci 25:61-78

Griffiths MH (2000) Long-term trends in catch and effort of commercial linefish off South Africa's Cape Province. S Afr J Mar Sci 22:81-110

* Griffiths MH, Wilke CG (2002) Long term movement patterns of five temperate-reef fishes (Pisces: Sparidae): implications for marine reserves. Mar Freshw Res 53: 233-244

* Griffiths SP, Zischke MT, Tonks ML, Pepperell JG, Tickell S (2013) Efficacy of novel sampling approaches for surveying specialised recreational fisheries. Rev Fish Biol Fish 23:395-413

Hilborn R, Walters CJ (1992) Quantitative fisheries stock assessment: choice, dynamics and uncertainty. Chapman and Hall, New York, NY

* Jiménez MP, Sobrino I, Ramos F (2004) Objective methods for defining mixed-species trawl fisheries in Spanish waters of the Gulf of Cádiz. Fish Res 67:195-206

Kaufman L, Rousseeuw PJ (1990) Finding groups in data: an introduction to cluster analysis. John Wiley, New York, NY

Kerwath SE, Winker H, Götz A, Attwood CG (2013a) Marine protected area improves yield without disadvantaging fishers. Nat Commun 4:2347

Kerwath SE, Wilke CG, Götz A (2013b) The effects of barotrauma on five species of South African line-caught fish. Afr J Mar Sci 35:243-252

Mann BQ, Kerwath SE (2013) Red steenbras (Petrus rupestis). In: Mann BQ (ed) Southern African marine linefish species profiles. Special Publication No. 9, Oceanographic Research Institute, Durban, p 252-254

Mann BQ, Buxton CD, Pollard D, Carpenter KE, Winker H (2014) Petrus rupestris. The IUCN Red List of Threatened Species 2014:e.T170247A1300995. doi:10.2305/IUCN.UK. 2014-3.RLTS.T170247A1300995.en (accessed 01 October 2018)

*Mann BQ, Winker H, Maggs J, Porter S (2016) Monitoring the recovery of a previously exploited surf-zone habitat in the St Lucia Marine Reserve using a no-take sanctuary area as a benchmark. Afr J Mar Sci 38:423-441

McClenachan L (2009) Historical declines of goliath grouper populations in South Florida, USA. Endang Species Res 7:175-181

Musick JA, Harbin MM, Berkeley SA, Burgess GH and others (2000) Marine, estuarine, and diadromous fish stocks at risk of extinction in North America (exclusive of Pacific salmonids). Fisheries (Bethesda, Md) 25:6-30

Parker D, Winker H, Attwood CG, Kerwath SE (2016) Dark times for dageraad Chrysoblephus cristiceps: evidence for stock collapse. Afr J Mar Sci 38:341-349

Pelletier D, Ferraris J (2000) A multivariate approach for defining fishing tactics from commercial catch and effort data. Can J Fish Aquat Sci 57:51-65

Penney AJ, Wilke CG (1992) The red steenbras: A species under siege? In: Beckley LE, van der Elst RP (eds) Fish, fishers and fisheries. Proc $2^{\text {nd }}$ South African Marine Linefish Symp, 23-24 Oct 1992, Durban. Oceanographic Research Institute, Cape Town, p 22-24

* Penney AJ, Mann-Lang JB, van der Elst RP, Wilke CG (1999) Long-term trends in catch and effort in the KwaZuluNatal nearshore linefisheries. S Afr J Mar Sci 21:51-76

Post JR, Sullivan M, Cox S, Lester NP and others (2002) Canada's recreational fisheries: The invisible collapse? Fisheries (Bethesda, Md) 27:6-17

Richardson EA, Kaiser MJ, Edwards-Jones G, Ramsay K (2006) Trends in sea anglers' catches of trophy fish in relation to stock size. Fish Res 82:253-262

Rose GA, Kulka DW (1999) Hyperaggregation of fish and fisheries: how catch-per-unit-effort increased as the northern cod (Gadus morhua) declined. Can J Fish Aquat Sci 56:118-127

Sadovy Y, Kulbicki M, Labrosse P, Letourneur Y, Lokani P, Donaldson TJ (2003) The humphead wrasse, Cheilinus undulatus: synopsis of a threatened and poorly known giant coral reef fish. Rev Fish Biol Fish 13:327-364

Sauer WH, Penney AJ, Erasmus C, Mann BQ, Brouwer SL, Lamberth SJ, Stewart TJ (1997) An evaluation of attitudes and responses to monitoring and management measures for the South African boat-based linefishery. S Afr J Mar Sci 18:147-163

Shiffman DS, Gallagher AJ, Wester J, Macdonald CC, Thaler AD, Cooke SJ, Hammerschlag N (2014) Trophy fishing for species threatened with extinction: a way forward building on a history of conservation. Mar Policy 50:318-322

* Smale MJ (1988) Distribution and reproduction of the reef fish Petrus rupestris (Pisces: Sparidae) off the coast of South Africa. S Afr J Zool 23:272-287

*Solano-Fernandez S, Attwood CG, Chalmers R, Clark BM and others (2012) Assessment of the effectiveness of South Africa's marine protected areas at representing ichthyofaunal communities. Environ Conserv 39: 259-270

* Stephens A, MacCall A (2004) A multispecies approach to subsetting logbook data for purposes of estimating CPUE. Fish Res 70:299-310

* Struyf A, Hubertt M, Rousseeuw PJ (1996) Clustering in an object-oriented environment. J Stat Softw 1:1-30

* Winker H, Kerwath SE, Attwood CG (2013) Comparison of two approaches to standardize catch-per-unit-effort for targeting behaviour in a multispecies hand-line fishery. Fish Res 139:118-131

Winker H, Kerwath SE, Attwood CG (2014) Proof of concept for a novel procedure to standardize multispecies catch and effort data. Fish Res 155:149-159

Wood SN (2006) Generalized additive models: an introduction with R. CRC Press, Boca Raton, FL

Woodward RT, Griffin WL (2003) Size and bag limits in recreational fisheries: theoretical and empirical analysis. Mar Resour Econ 18:239-262 
Appendix. Standardisation of probability of encounter: proof of concept

Central to inferring trends in relative abundance from probabilities of encounter (PE) for rare species is the assumption that if the PE decreases below a certain threshold, the information content in the non-zero observations is minimal, so that the relationship between $\mathrm{PE}$ and abundance becomes approximately linear close to its origin. To provide proof-of-concept, we conducted a small simulation experiment. For ease of illustration, we assume that the sampling of the true population is based on counts per unit sampling effort and that the resulting mean count, $\mu$, is proportional to the population's abundance, $N$. We then generated a large number $(\mathrm{n}=$ 1000) of random count observations from a Poisson distribution over a wide range of mean values $(\mu=$ $0.1-100)$. This process was repeated by increasingly inflating the variance $\left(\sigma^{2}\right)$ to induce over-dispersion through quasi-Poisson process, with $\sigma^{2}=\varphi \mu$, where $\varphi$ is the dispersion parameter. If $\varphi=1$, the underlying distribution follows a Poisson process that becomes overdispersed for $\varphi>1$.
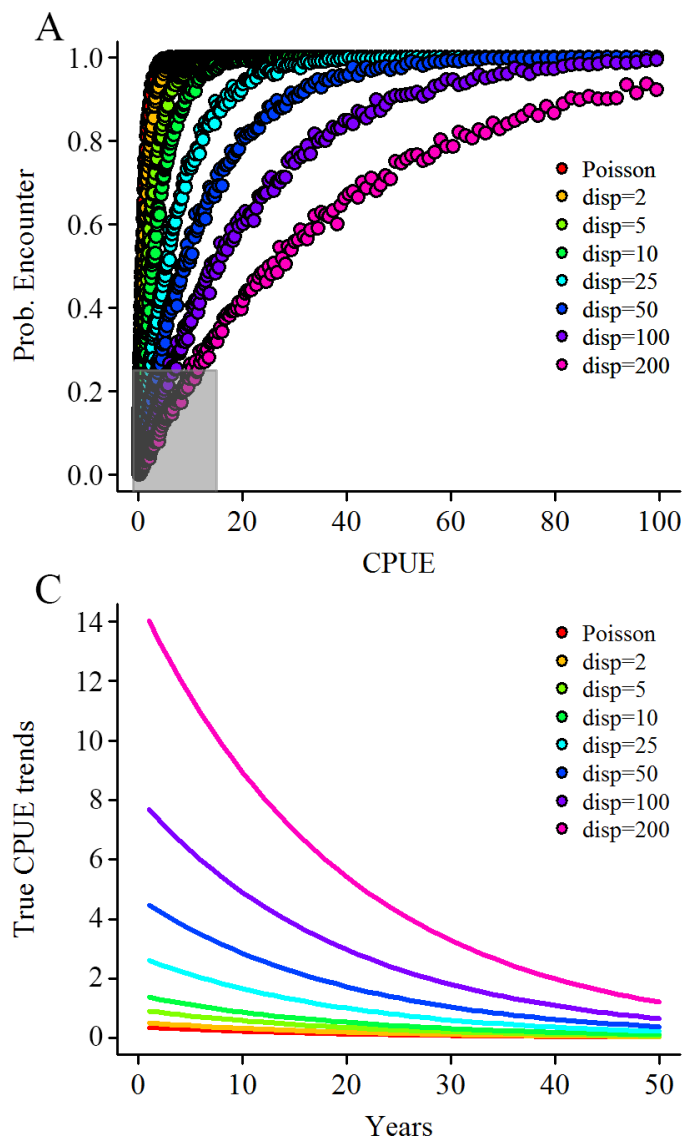

The mean probability of encounter $\left(\mathrm{PE}_{i}\right)$ for each mean count $\mu_{i}$ was calculated as the ratio of non-zero observations to the total number of simulated count observations for $\mu_{i}$. The resulting relationships show the expected nonlinear asymptotic relationship between $\mu_{i}$ and $\mathrm{PE}_{i}$ (Fig. A1A). However, when only considering the range of $\mathrm{PE}$ below 0.25 , the relationship is approximately linear, which holds for a wide range of dispersion values (Fig. A1B). The slope at the origin decreases with increasing over-dispersion.

For further illustration, we modelled declines in mean counts $\mu_{y}$ over $50 \mathrm{yr}(t)$ of the form $\mu_{t}=\mu_{1} \exp (-0.05(t-1))$, where the mean count $\mu_{1}$ in year $t=1$ was set to the mean count that corresponds to a $\mathrm{PE}=0.25$ for each of the considered dispersion parameters $\varphi_{j}$ (Fig. A1C). When normalized by their means, the trends $\mu_{t, j} /$ mean $\left(\mu_{t, j}\right)$ for each $\varphi_{j}$ are identical. On comparison to this 'true' trend in mean counts, it can be demonstrated the corresponding decline in the normalized $\mathrm{PE}_{t, j} /$ mean $\left(\mathrm{PE}_{t, j}\right)$ is proportional for $\mathrm{PE}_{t, j}$ $<0.25$ (Fig. A1D).
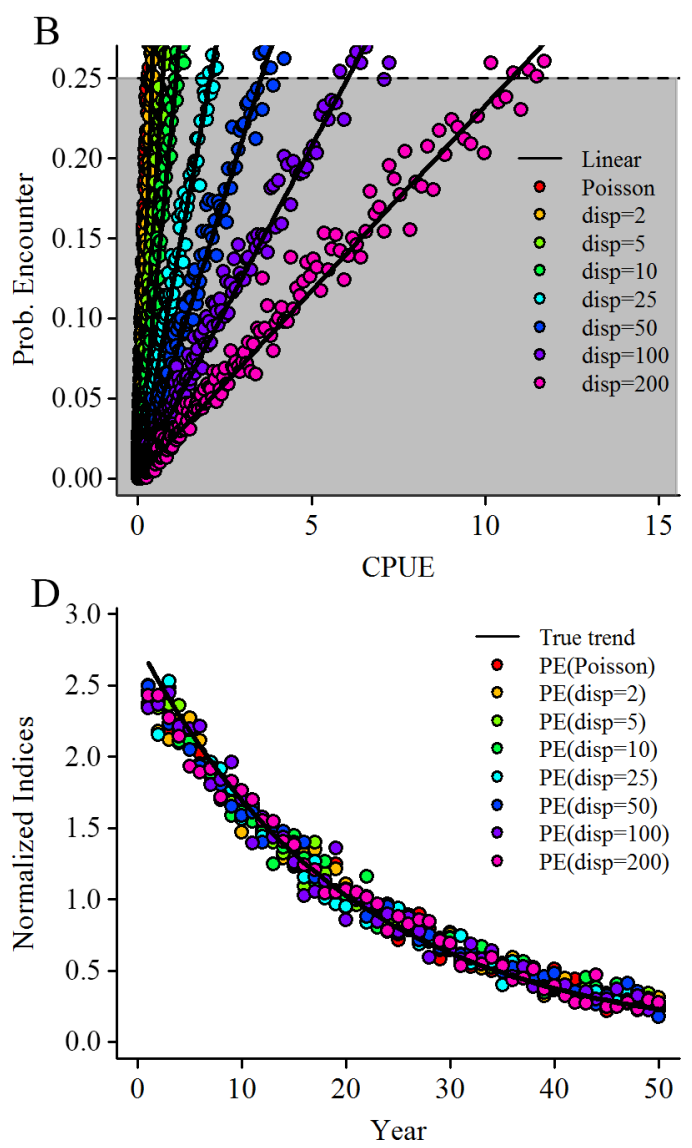

Fig. A1. Simulation results showing (A) the relationship between catch per unit effort (CPUE) and the probability of encounter (PE) for a wide range of over-dispersion (disp) parameter values, and the grey area highlighting (B) the approximately linear relationship between CPUE and the PE, if PE $<0.25$; (C) 'true' CPUE trends at rate of decline of 0.05 for range of disp parameter values; and (D) comparison of trends between the normalized 'true' trends and the normalized trends in the simulated PE 